\title{
Chest pain without established ischaemic heart disease in primary care patients: associated comorbidities and mortality
}

\author{
Ana Ruigómez, Elvira L Massó-González, Saga Johansson, \\ Mari-Ann Wallander and Luis A García-Rodríguez
}

\begin{abstract}
Background

Ischaemic heart disease (IHD) can be excluded in the majority of patients with unspecific chest pain. The remainder have what is generally referred to as noncardiac chest pain, which has been associated with gastrointestinal, neuromusculoskeletal, pulmonary, and psychiatric causes.
\end{abstract}

Aim

To assess morbidity and mortality following a new diagnosis of non-specific chest pain in patients without established IHD.

Design of study

Population-based cohort study with nested case-control analysis.

Setting

UK primary care practices contributing to the General Practice Research Database.

\section{Method}

Patients aged 20-79 years with chest pain who had had no chest pain consultation before 2000 and no IHD diagnosis before 2000 or within 2 weeks after the index date were selected from the General Practice Research Database. The selected 3028 patients and matched controls were followed-up for 1 year.

Results

The incidence of chest pain in patients without established IHD was 12.7 per 1000 person-years. In the year following the index date, patients who had chest pain but did not have established IHD were more likely than controls to receive a first IHD diagnosis (hazard ratio $[\mathrm{HR}]=18.2,95 \%$ confidence interval $[\mathrm{Cl}]$ $=11.6$ to 28.6$)$ or to die $(\mathrm{HR}=2.3,95 \% \mathrm{Cl}=1.3$ to 4.1). Patients with chest pain commonly had a history of gastro-oesophageal reflux disease (GORD; odds ratio $[\mathrm{OR}]=2.0,95 \% \mathrm{Cl}=1.5$ to 2.7 ) or went on to be diagnosed with GORD (risk ratio $4.5,95 \% \mathrm{Cl}=3.1$ to 6.4).

\section{Conclusion}

Patients with chest pain but without established IHD were found to have an increased risk of being diagnosed with IHD. Chest pain in patients without established IHD was also commonly associated with GORD.

\section{Keywords}

chest pain; gastro-oesophageal reflux disease; mortality; myocardial ischaemia; primary healthcare.

\section{INTRODUCTION}

There is a well-known association between chest pain and heart disease, and this is a major cause of concern to both patients and physicians. However, ischaemic heart disease (IHD) can be excluded in the majority of patients presenting with unspecific chest pain while the remainder are considered to have what is generally called non-cardiac chest pain. Non-specific chest pain is common in the community; a recent Australian population-based study evaluating non-cardiac chest pain in 1000 individuals using a validated questionnaire reported that it affected up to $32 \%$ of men and $33 \%$ of women. ${ }^{1}$ Two other large population-based studies reported similar prevalence estimates. ${ }^{2,3}$

Non-cardiac chest pain presents a diagnostic challenge; the application of a range of diagnostic techniques to patients with non-specific chest pain has shown that it is associated with gastrointestinal, neuromusculoskeletal, pulmonary, and psychiatric diseases. ${ }^{4}$ Population-based studies have identified a similarly wide range of associated factors. ${ }^{4}$ Gastro-

A Ruigómez, PhD, MD, senior researcher; EL Massó-González; $M S c$, researcher, LA García-Rodríguez, MSc, MD, director, Spanish Centre for Pharmacoepidemiologic Research (CEIFE), Madrid, Spain. S Johansson, PhD, MD, senior principal scientist, Sahlgrenska Academy, Institute of Medicine, Gothenburg, Sweden. M-A Wallander, PhD, senior scientist, Department of Public Health and Caring Science, Uppsala University, Sweden.

Address for correspondence

Dr Ana Ruigómez, CEIFE, Almirante 28 (2º), Madrid 28004, Spain. E-mail: aruigomez@ceife.es

Submitted: 13 May 2008; Editor's response: 30 July 2008; final acceptance: 18 August 2008.

(B) British Journal of General Practice

This is a full-length article of an abridged version published in print and originally published online first. Cite this version as: Br J Gen Pract 2009 DOI: 10.3399/bjgp09X407054 (abridged text, in print: Br J Gen Pract 2009; 59: 198-205). 
oesophageal reflux disease (GORD) has been reported to be present in up to $60 \%$ of people with chest pain, ${ }^{1,5}$ musculoskeletal conditions have a prevalence of $25-35 \%$ in individuals with noncardiac chest pain, ${ }^{1,6}$ and associations with anxiety and depression have also been observed. ${ }^{6,7}$

The large Australian population-based study by Eslick et al revealed that only $23 \%$ of individuals with non-cardiac chest pain had consulted a physician within the previous year, compared with $48 \%$ of individuals with cardiac chest pain. ${ }^{1}$ Given the low consultation rate for non-specific chest pain, it is unclear how the prevalence estimates and comorbidities reported by previous population-based studies relate to primary care. Here, the General Practice Research Database was utilised, a large longitudinal database of UK primary care data, to describe the characteristics, treatment patterns, and comorbidities of a cohort of patients newly diagnosed with chest pain, but without established IHD, in comparison with a cohort of individuals without a diagnosis of chest pain. Further aims were evaluating the 1-year risk of IHD and other specific comorbidities, as well as estimating mortality in both cohorts.

\section{METHOD}

The data for this population-based study were extracted from the UK General Practice Research Database. This large longitudinal primary care database contains information entered by some 1500 primary care physicians covering a population of three million individuals representative of the UK's general population. ${ }^{8}$ The primary care physicians hold the complete medical records of all individuals registered with them, including demographics, diagnoses, prescriptions, and referrals. This information is anonymised and sent to the Medicines and Healthcare products Regulatory Agency for use in research projects. The accuracy and completeness of the database has been validated by previous studies $^{9,10}$ and mortality data have been used successfully in several analyses. ${ }^{11-13}$

\section{Study population and design}

The source population for this study was made up of individuals aged 20-79 years during 2000, who had been enrolled with their primary care physician for at least 2 years before the start date, and had had at least one healthcare consultation in the preceding 3 years. From this source population, patients who had had an IHD diagnosis, chest pain consultation, cardiac surgery, or cancer before 2000 were excluded, as well as women who were pregnant during the study period.

To identify cases of non-specific chest pain, all patients in the source population were followed-up

\section{How this fits in}

There is a well-known association between chest pain and heart disease.

However, ischaemic heart disease (IHD) can be excluded clinically in the majority of patients with chest pain. The remaining patients are a diagnostic challenge, as many conditions are believed to be associated with non-cardiac

chest pain. This article highlights that chest pain should be considered a marker of IHD even in patients without established IHD. It is also a marker for gastro-oesophageal reflux disease and other diseases.

from 1 January 2000 until the first occurrence of one of these endpoints:

- register code of chest pain recorded using Oxford Medical Information Systems/Read codes that did not specify a type or location for the chest pain (Appendix 1);

- diagnosis of cancer;

- 80 years of age;

- death; or

- the end of study period (31 December 2000).

To avoid selecting patients in whom IHD was immediately obvious at inclusion, patients who were diagnosed with IHD within 2 weeks of the first consultation for chest pain were excluded. Individuals were also excluded if they were current users of nitrates with at least three prescriptions before the first consultation. To ensure access to all the required information, only patients registered in practices with at least 1 year of follow-up data were included in the final analysis.

The same source population and eligibility criteria were used to select an age- and sexmatched control cohort who did not have any record of chest pain. An index date in 2000 was randomly assigned to each of these individuals. Patients in both cohorts were followed for 1 year after the index date, and the risk of mortality, incident IHD, and other specific morbidities were estimated.

\section{Data collection}

Data regarding demographics, risk factors (smoking status, body mass index [BMI], and alcohol intake), and comorbidities were collected from computer records, as were the number of consultations, admissions, and referrals in the year before and the year after the index date. New prescriptions of the following drugs in the month were assessed after the index date among patients who were not prescribed them in the previous year:

- non-steroidal anti-inflammatory drugs (NSAIDs); 
- paracetamol;

- proton-pump inhibitors (PPIs);

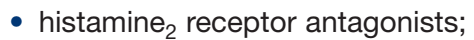

- antidepressants;

- anxiolytics;

- beta $_{2}$-agonists; and

- oral steroids.

The cause of death as registered by the physician was ascertained for all deaths occurring during the first year of follow-up. Patients who die while registered with a practice have their registration status changed in the database. If the cause of death is known, it is entered together with the date of death. In cases where the cause of death is unknown, the code for 'cause of death unknown' is entered, and the physician is asked to enter any relevant indications and remarks in the comments section. In the present study, the cause of death registered by the physician was confirmed

\section{Table 1. Demographic characteristics and healthcare utilisation and their association with a first consultation for non-specific chest pain.}

\begin{tabular}{|c|c|c|c|}
\hline & $\begin{array}{l}\text { Patients with chest pain } \\
\qquad(n=3028), n(\%)\end{array}$ & $\begin{array}{c}\text { Controls }^{\mathrm{a}} \\
(n=9000), n(\%)\end{array}$ & $\begin{array}{l}\text { Odds ratio }^{b} \\
(95 \% \mathrm{Cl})\end{array}$ \\
\hline \multicolumn{4}{|l|}{ Age, years } \\
\hline 20-39 & $865(28.6)$ & 2534 (28.2) & $\mathrm{n} / \mathrm{a}$ \\
\hline $40-59$ & $1355(44.7)$ & $4024(44.7)$ & \\
\hline $60-80$ & $808(26.7)$ & $2442(27.1)$ & \\
\hline \multicolumn{4}{|l|}{ Sex } \\
\hline Male & $1527(50.4)$ & $4536(50.4)$ & $\mathrm{n} / \mathrm{a}$ \\
\hline Female & $1501(49.6)$ & $4464(49.6)$ & \\
\hline \multicolumn{4}{|c|}{ Smoking status $^{c}$} \\
\hline Non-smoker & $1456(48.1)$ & $4551(50.6)$ & 1 \\
\hline Smoker & 999 (33.0) & $2283(25.4)$ & $1.3(1.2$ to 1.4$)$ \\
\hline Ex-smoker & $278(9.2)$ & $829(9.2)$ & $1.0(0.8$ to 1.1$)$ \\
\hline \multicolumn{4}{|c|}{ Body mass index, ${ }^{d} \mathrm{~kg} / \mathrm{m}^{2}$} \\
\hline$<20.0$ & $181(6.0)$ & $498(5.5)$ & $1.0(0.9$ to 1.3$)$ \\
\hline $20.0-24.9$ & $998(33.0)$ & $2936(32.6)$ & 1 \\
\hline 25.0-29.9 & 887 (29.3) & $2456(27.3)$ & $1.0(0.9$ to 1.1$)$ \\
\hline$\geq 30.0$ & $452(14.9)$ & $1110(12.3)$ & 1.1 (0.9 to 1.2$)$ \\
\hline \multicolumn{4}{|c|}{ Alcohol use, ${ }^{e}$ units/week } \\
\hline None & $1018(33.6)$ & $2592(28.8)$ & 1 \\
\hline $1-15$ & $1153(38.1)$ & 3445 (38.3) & $0.9(0.8$ to 1.0$)$ \\
\hline $16-42$ & $264(8.7)$ & $773(8.6)$ & $0.9(0.7$ to 1.0$)$ \\
\hline$>42$ & $137(4.5)$ & $276(3.1)$ & $1.1(0.9$ to 1.4$)$ \\
\hline \multicolumn{4}{|c|}{ Primary care consultations in previous year } \\
\hline None & $328(10.8)$ & $2149(23.9)$ & 1 \\
\hline $1-4$ & $1287(42.5)$ & $4505(50.1)$ & 2.0 (1.7 to 2.2$)$ \\
\hline$\geq 5$ & $1413(46.7)$ & $2346(26.1)$ & 4.3 (3.8 to 5.0$)$ \\
\hline \multicolumn{4}{|c|}{ Referrals and hospitalisation in previous year } \\
\hline None & $1528(50.5)$ & $5717(63.5)$ & 1 \\
\hline$\geq 1$ & $1500(49.5)$ & $3283(36.5)$ & $1.2(1.1$ to 1.3$)$ \\
\hline
\end{tabular}

${ }^{a}$ Controls were age and sex matched to the non-specific chest pain cases. ${ }^{\circ}$ Odds ratio estimates and $95 \% \mathrm{Cls}$ were adjusted by age and sex and consultations in the prior year, using logistic regression. 'In $14.9 \%$ of controls and $9.7 \%$ of patients, smoking status was not recorded. In $22.2 \%$ of controls and $16.8 \%$ of cases, body mass index could not be calculated. eln $21.3 \%$ of controls and $15.1 \%$ of cases, alcohol use was not recorded. through manual review of the computer patient profiles for all deaths that occurred within the first year of follow-up.

\section{Statistical analyses}

The incidence of non-specific chest pain was estimated according to age and sex among patients without prior IHD as the number of patients identified with a first record of chest pain divided by the total number of person-years in each stratum.

The occurrence of various health-related factors were analysed, including prescribed drug use and diagnoses of chronic diseases in the previous year, in patients with a diagnosis of non-specific chest pain and in a control cohort with no chest pain diagnosis. Logistic regression analysis was used to estimate the odds ratios (ORs) and 95\% confidence intervals (Cls) of the studied factors in association with nonspecific chest pain. OR estimates were adjusted by age, sex, and number of visits to the primary care physician in the previous year. The risk of onset of a new comorbidity in the year following the first consultation for non-specific chest pain was estimated as a risk ratio, comparing the risk of patients in the non-specific chest pain group developing a new condition (proportion of new cases of a specific outcome among individuals free of this diagnosis before the index date) with the same risk for individuals in the control group. One-year mortality was estimated from the number of patients who died in the year following the index date. Proportional hazards regression analysis was used to estimate the hazard ratio (HR) and $95 \% \mathrm{Cl}$ for death and IHD diagnosis associated with non-specific chest pain, adjusting for age, sex, and other healthrelated factors.

To avoid potential investigation bias, a sensitivity analysis on the follow-up of IHD was also performed. Patients who received a diagnosis of IHD within the 3 months following the non-specific chest pain consultation were excluded.

\section{RESULTS}

A cohort of 6343 potential cases were identified from the source population of 628449 individuals, from which the patients who had non-specific chest pain during 2000 were identified and registered with a primary care physician, with at least 1 year of followup. This gave a cohort of 3028 incident cases with non-specific chest pain, defined as a first ever consultation for non-specific chest pain not related to IHD. An age- and sex-matched control cohort who did not have any record of chest pain $(n=9000)$ was selected from the same source population using the same eligibility criteria.

The incidence of non-specific chest pain believed 
to be non-cardiac in 2000 was estimated to be 12.7 per 1000 person-years. The incidence was slightly higher in males (13.1 per 1000 person-years) than in females (12.6 per 1000 person-years) and increased from 10.6 per 1000 person-years at age 20-39 years to 15.6 per 1000 person-years at age of $70-79$ years. In comparison with an age- and sex-matched control cohort, patients with non-specific chest pain were significantly more likely to be smokers $(O R=1.3$, $95 \% \mathrm{Cl}=1.2$ to 1.4 ; Table 1). Alcohol intake and BMI were not significantly associated with non-specific chest pain. In the year before diagnosis, patients newly diagnosed with non-specific chest pain consulted their physician and were hospitalised significantly more frequently than individuals without non-specific chest pain.

\section{Comorbidities in the year before non-specific chest pain consultation}

Patients with non-specific chest pain were observed to be more likely than controls to have had an upper gastrointestinal complaint in the year before diagnosis. A prior consultation for GORD (OR $=2.0$, $95 \% \mathrm{Cl}=1.5$ to 2.7 ) or dyspepsia (OR $=1.7,95 \% \mathrm{Cl}$ $=1.4$ to 2.2 ) was significantly associated with an increased risk of non-specific chest pain (Table 2). Psychological conditions such as anxiety $(\mathrm{OR}=1.6$, $95 \% \mathrm{Cl}=1.2$ to 2.0 ) were also significantly associated with a new diagnosis of non-specific chest pain, and an association with sleep disorders and depression was also observed (Table 2). Nonspecific chest pain was also significantly associated with chronic obstructive pulmonary disease (COPD; $\mathrm{OR}=1.7,95 \% \mathrm{Cl}=1.1$ to 2.7$)$, musculoskeletal disease $(\mathrm{OR}=1.2,95 \% \mathrm{Cl}=1.1$ to 1.4$)$, and a range of painful conditions (OR $=1.5,95 \% \mathrm{Cl}=1.3$ to 1.6 ) (Table 2).

\section{New treatment and new comorbidities in the following year}

Among those untreated at the index date, patients with non-specific chest pain were much more likely than controls to begin treatment with NSAIDs or paracetamol (Table 3). It was found that $3.6 \%$ of patients with non-specific chest pain started treatment with PPIs, compared with $0.1 \%$ of controls.

In the year after the index date, patients in the non-specific chest pain cohort were significantly more likely than controls to be newly diagnosed with GORD (risk ratio $=4.5,95 \% \mathrm{Cl}=3.1$ to 6.4 ; Table 4). In addition, they had at least a twofold significantly increased risk of being diagnosed with dyspepsia, asthma, pneumonia, stress, or anxiety compared with individuals without non-specific chest pain. Weaker significant associations were
Table 2. Comorbidity in the year before first consultation for non-specific chest pain.

\begin{tabular}{lccc} 
& $\begin{array}{c}\text { Patients with chest pain } \\
n=3028, n(\%)\end{array}$ & $\begin{array}{c}\text { Controls } \\
n=9000, n(\%)\end{array}$ & OR $^{\mathrm{b}}(95 \% \mathrm{Cl})$ \\
\hline GORD & $90(3.0)$ & $94(1.0)$ & $2.0(1.5$ to 2.7$)$ \\
\hline Dyspepsia & $170(5.6)$ & $214(2.4)$ & $1.7(1.4$ to 2.2$)$ \\
\hline Peptic ulcer & $9(0.3)$ & $12(0.1)$ & $1.7(0.7$ to 4.1$)$ \\
\hline IBS & $35(1.2)$ & $84(0.9)$ & $0.8(0.6$ to 1.3$)$ \\
\hline IBD & $11(0.4)$ & $12(0.1)$ & $1.9(0.8$ to 4.4$)$ \\
\hline Anxiety & $135(4.5)$ & $175(1.9)$ & $1.6(1.2$ to 2.0$)$ \\
\hline Depression & $191(6.3)$ & $302(3.4)$ & $1.2(1.0$ to 1.5$)$ \\
\hline Stress & $57(1.9)$ & $113(1.3)$ & $1.0(0.7$ to 1.4$)$ \\
\hline Sleep disorders & $84(2.8)$ & $122(1.4)$ & $1.3(1.0$ to 1.8$)$ \\
\hline COPD & $39(1.3)$ & $46(0.5)$ & $1.7(1.1$ to 2.7$)$ \\
\hline Asthma & $124(4.1)$ & $210(2.3)$ & $1.2(0.9$ to 1.5$)$ \\
\hline Musculoskeletal & $777(25.7)$ & $1507(16.7)$ & $1.2(1.1$ to 1.4$)$ \\
\hline Painful conditions & & $1636(18.2)$ & $1.5(1.3$ to 1.6$)$ \\
\hline
\end{tabular}

${ }^{a}$ Controls were age- and sex-matched to those patients with chest pain. ${ }^{b} \mathrm{OR}$ estimates with their $95 \% \mathrm{Cls}$ were adjusted by age and sex and consultations in the previous year, using logistic regression. The reference category in each case was the absence of the studied diagnosis. 'Painful conditions included headache, neuralgia, menstrual and inter-menstrual pain, female genital pain, eye pain, earache, nose pain, throat pain, mouth pain, respiratory pain, abdominal pain, rectal pain, urinary-tract pain, penile and testicular pain, skin pain, breast pain, limb pain, muscular and joint pain, neck pain, and generalised pain. COPD = chronic obstructive pulmonary disease. GORD = gastro-oesophageal reflux disease. IBD = inflammatory bowel disease. IBS = irritable bowel syndrome. $O R=$ odds ratio.

observed with depression and musculoskeletal conditions, and an association of non-specific chest pain with a new diagnosis of sleep disorders was observed (Table 4).

In the first year of follow-up, 137 patients in the non-specific chest pain group and 23 in the control group received a first diagnosis of IHD (Figure 1). The $\mathrm{HR}$ of an IHD diagnosis during the year following the

\begin{tabular}{|c|c|c|c|c|}
\hline & \multicolumn{2}{|c|}{$\begin{array}{c}\text { Non-specific } \\
\text { chest pain cases }\end{array}$} & \multicolumn{2}{|c|}{ Controls $^{\mathrm{b}}$} \\
\hline & $n$ & $\begin{array}{c}\text { new } \\
\text { users (\%) }\end{array}$ & $n$ & $\begin{array}{c}\text { new } \\
\text { users (\%) }\end{array}$ \\
\hline $\mathrm{H}_{2}$-RAs & 2432 & $68(2.8)$ & 7871 & $8(0.1)$ \\
\hline PPIs & 2590 & $93(3.6)$ & 8277 & $7(0.1)$ \\
\hline Antidepressants & s 2136 & $30(1.4)$ & 7329 & $11(0.2)$ \\
\hline Anxiolytics & 2572 & $10(0.4)$ & 8152 & $6(0.1)$ \\
\hline NSAIDs & 1069 & $80(7.5)$ & 4267 & $21(0.5)$ \\
\hline Paracetamol & 1357 & $83(6.1)$ & 5364 & $15(0.3)$ \\
\hline Beta $_{2}$-agonists & 2358 & $17(0.7)$ & 7637 & $7(0.1)$ \\
\hline Oral steroids & 2437 & $11(0.5)$ & 7835 & $9(0.1)$ \\
\hline \multicolumn{5}{|c|}{$\begin{array}{l}\text { aNew drug use was defined as a prescription during the first } \\
\text { month following the index date among those not receiving } \\
\text { the drug before the index date. }{ }^{\circ} \text { Controls were age- and sex- } \\
\text { matched to patients. } H_{2}-R A s=\text { histamine } 2 \text { receptor } \\
\text { antagonists. NSAIDs = non-steroidal anti-inflammatory } \\
\text { drugs. PPIs = proton pump inhibitors. }\end{array}$} \\
\hline
\end{tabular}




\section{Table 4. Risk of new onset of specific comorbidity in the cohort with non-specific chest pain compared with controls.}

\begin{tabular}{|c|c|c|c|c|c|}
\hline & \multicolumn{2}{|c|}{$\begin{array}{l}\text { Cohort with } \\
\text { chest pain }\end{array}$} & \multicolumn{2}{|c|}{ Controls } & \multirow{2}{*}{$\begin{array}{l}\text { Risk ratio of a } \\
\text { new diagnosis } \\
(95 \% \mathrm{Cl})\end{array}$} \\
\hline & $n^{\mathrm{a}}$ & New cases & $n^{\mathrm{a}}$ & New cases & \\
\hline \multicolumn{6}{|l|}{ Gastrointestinal } \\
\hline GORD & 2612 & 80 & 8287 & 55 & 4.5 (3.1 to 6.4$)$ \\
\hline Dyspepsia & 2297 & 103 & 7681 & 79 & 4.1 (3.0 to 5.6 ) \\
\hline Peptic ulcer disease & 2910 & 7 & 8786 & 7 & 2.7 (0.9 to 8.1 ) \\
\hline IBS & 2775 & 17 & 8540 & 22 & 1.8 (0.9 to 3.4$)$ \\
\hline \multicolumn{6}{|l|}{ Psychological } \\
\hline Anxiety & 2469 & 66 & 7910 & 86 & 2.0 (1.4 to 2.8 ) \\
\hline Depression & 2300 & 75 & 7585 & 115 & 1.7 (1.2 to 2.3$)$ \\
\hline Stress & 2739 & 46 & 8477 & 58 & 2.0 (1.4 to 3.0$)$ \\
\hline Sleep disorders & 2614 & 40 & 8265 & 64 & 1.5 (1.0 to 2.3 ) \\
\hline \multicolumn{6}{|l|}{ Respiratory } \\
\hline Asthma & 2641 & 27 & 8182 & 17 & 3.9 (2.1 to 7.4$)$ \\
\hline COPD & 2922 & 9 & 8833 & 25 & 0.9 (0.4 to 2.0$)$ \\
\hline Pneumonia & 2961 & 14 & 8834 & 9 & 3.6 (1.5 to 8.7$)$ \\
\hline Musculoskeletal & 1115 & 170 & 4538 & 353 & 1.9 (1.6 to 2.3 ) \\
\hline
\end{tabular}

anumer of patients without the specific diagnosis in the 12 months before chest pain consultation. ${ }^{b}$ Risk ratio of the risk of first-time diagnosis of specific outcomes in the group with non-specific chest pain compared to controls. Estimates are adjusted for age, sex, visits to the GP in the previous year, BMI, alcohol use, smoking, and chest pain diagnosis, using logistic regression. $C O P D=$ chronic obstructive pulmonary disease; $G O R D=$ gastrooesophageal reflux disease; IBS = irritable bowel syndrome.

index date was $18.2(95 \% \mathrm{Cl}=11.6$ to 28.6$)$ for patients with non-specific chest pain compared with controls. Among those developing IHD, an episode of acute myocardial infarction was confirmed in 12 patients in the non-specific chest pain group and eight controls, corresponding to an HR of a first myocardial infarction associated with non-specific chest pain of $4.1(95 \% \mathrm{Cl}=1.6$ to 10.3$)$. Of the patients with non-specific chest pain who developed IHD, most were males and were significantly older
Figure 1. Time to new diagnosis of IHD during the 1-year follow-up period. than those who did not develop IHD. These patients also had several known cardiovascular risk factors such as hypertension and hyperlipidaemia, and had

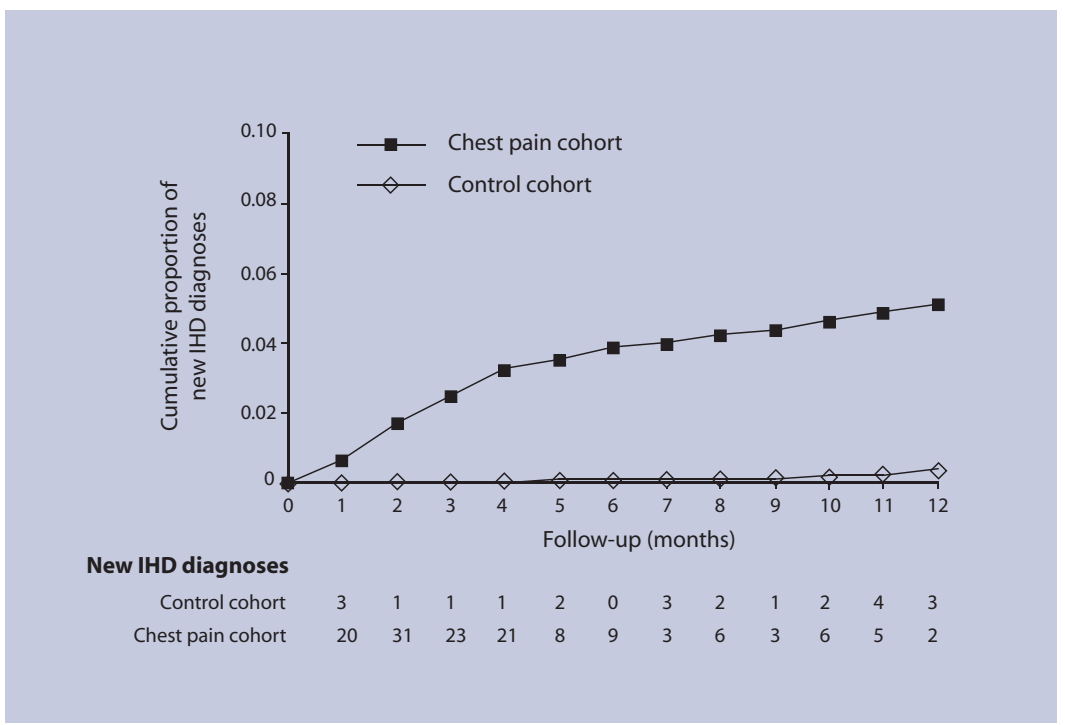

experienced repeated consultations for chest pain (data not shown). Indeed, a sensitivity analysis using the cut-off criteria of the first 3 months of follow-up showed that the association with chest pain decreases in strength, but not significance (HR 11.3; $95 \% \mathrm{Cl}=6.7$ to 19.1 ).

One-year mortality among patients with nonspecific chest pain (9.8 per 1000 persons) was higher than for controls (3.9 per 1000 persons). The HR of death associated with non-specific chest pain in the first year was $2.3(95 \% \mathrm{Cl}=1.3$ to 4.1$)$. There were several causes of death in the group of patients with non-specific chest pain, including cancer, cerebrovascular disease, and ischaemic disease, while cancer was the main cause of death in the control group (33\% of patients). Crude and adjusted HRs are presented in Appendix 2.

\section{DISCUSSION}

\section{Summary of main findings}

A total of 3028 patients were identified without established IHD who had their first ever consultation for chest pain in UK primary care during 2000. The chest pain was considered to be non-cardiac due to the fact that patients did not have a prior IHD diagnosis or receive one within the 2 weeks following the chest pain consultation. On this basis, the incidence of non-specific chest pain was shown to be 12.7 per 1000 person-years. Patients with nonspecific chest pain were more likely to be smokers and to have consulted their physician more frequently than those individuals who had no chest pain.

In the first year of follow-up, patients with chest pain but no history of IHD were more likely than controls to receive a first diagnosis of IHD. The results also show that, not only are patients with nonspecific chest pain, that is believed to be noncardiac in origin, more likely to have a history of GORD, but that, after IHD, GORD is the most strongly associated comorbidity diagnosed in the year following chest pain consultation. Furthermore, it was found that 1-year mortality was higher for patients with non-specific chest pain than for controls. This increased risk of death was consistent with previous findings, ${ }^{14}$ and was mainly due to IHDand cancer-related deaths.

\section{Strengths and limitations of this study}

The use of the General Practice Research Database allowed data for this study to be collected prospectively from a large representative sample of the UK general population registered with a primary care physician. Consultation rates for non-specific chest pain are known to be low, ${ }^{7}$ but the actual incidence of non-specific chest pain is likely to be higher than was assessed. In order to avoid as much 
potential consultation bias as possible, it was requested that both groups of patients (those with and without chest pain) had undergone at least one healthcare consultation within the previous 3 years.

As is common in epidemiological studies, nonspecific chest pain was defined as unexplained chest pain in the absence of prior IHD. Although the results are not necessarily generalisable to the broad population of patients diagnosed as having non-cardiac chest pain in primary care, they are representative of the broader population of patients consulting with chest pain in whom no underlying cause is immediately reached. The study relied on the diagnosis entered by the primary care physicians and, therefore, included potential misdiagnoses. Indeed, a high incidence of IHD was found in the year following non-specific chest pain consultation among patients who were free of IHD before the index date. This suggests that a cardiovascular diagnosis was missed in some cases. A 2-week period was allocated following the first consultation for chest pain to allow for a diagnosis of IHD to occur. Although this time frame was arbitrary, data from Figure 1 showing that IHD diagnoses occurred gradually over the 1-year follow-up period suggest that these results would not be markedly affected by extending this period of time. Indeed, a sensitivity analysis using a wider cutoff criterion of 3 months showed that the association with chest pain decreases in strength, but not significance.

It should also be noted that the database does not definitively link subsequent diagnoses to chest pain; as such, although many patients did not receive any diagnosis during the study period, others may have received more than one. Indeed, the data shows that, at most, only $20 \%$ of the cohort with non-specific chest pain received a new diagnosis of one of the studied conditions during the follow-up period.

\section{Comparison with existing literature}

A recent review reported that up to $39 \%$ of patients presenting with chest pain for the first time to emergency care are ultimately diagnosed with coronary artery disease..$^{15}$ It has also been shown that approximately $4 \%$ of patients presenting in emergency care with chest pain are diagnosed with acute myocardial infarction. ${ }^{16} \mathrm{~A}$ multicentre cohort study of patients diagnosed with non-cardiac chest pain attending rapid-access chest pain clinics reported that $2.73 \%$ were subsequently diagnosed with angina. ${ }^{17}$ As the data are based on recorded diagnoses rather than patient recall, as were previous studies, ${ }^{1,6}$ the results are not completely comparable. The data reveal that, among patients presenting with unspecific chest pain and without a history of coronary disease, over $5 \%$ were diagnosed with IHD in the year following their consultation, a rate 18 times higher than in the control population.

GORD. Previous studies that investigated patients with non-cardiac chest pain in secondary care using oesophageal endoscopy and $\mathrm{pH}$ monitoring have reported the oesophagus to be a potential origin of non-cardiac chest pain in up to two-thirds of patients, with GORD being the most likely cause. ${ }^{18-21}$ A study in UK primary care reported that IHD was ruled out in half of all patients consulting with chest pain, and that the chest pain had an oesophageal origin in $10 \%$ of patients. ${ }^{22}$ Similarly, in this study it was found that $10 \%$ of patients with non-specific chest pain reported gastrointestinal complaints such as GORD, dyspepsia, or peptic disease during the year preceding the index date, and that $3 \%$ of patients with non-specific chest pain had previously received a GORD diagnosis.

In the year following a first consultation for nonspecific chest pain, the strongest new association with chest pain after IHD was GORD. According to the recent Montreal Definition of GORD, non-cardiac chest pain is considered an 'atypical' GORD symptom. ${ }^{23}$ However, confirmation of GORD as the cause of non-specific chest pain in individual patients is often difficult and may need expensive, prolonged $\mathrm{pH}$-monitoring or manometry. ${ }^{15,24,25}$

In this study, among those patients not previously consulting for reflux symptoms, there was a greater than fourfold increased risk of developing GORD or dyspepsia after the initial consultation for nonspecific chest pain. Furthermore, it has been shown that, among those untreated at the index date, patients with non-specific chest pain were much more likely than controls to begin new treatment with PPIs, which is likely to be a reflection of new GORD diagnoses. The new PPI prescriptions may also indicate their usage as a diagnostic tool for GORD; a recent systematic review supports the use of a PPI as a cost-effective aid in the diagnosis of GORD in patients with non-cardiac chest pain. ${ }^{26}$

Psychological conditions. It has been shown that there is an association between non-specific chest pain and diagnoses of anxiety or depression in the year before the index date. Other studies have shown that up to $30 \%$ of patients with non-cardiac or non-specific chest pain experience panic disorder and anxiety. ${ }^{27-29}$ The magnitude of the association observed with anxiety is similar to that reported previously in cross-sectional studies. ${ }^{1}$ It was also found that patients with non-specific chest pain had an up to twofold increased risk of receiving a new 
diagnosis of stress, anxiety, or depression, which is in line with cross-sectional data from a previous population-based study. ${ }^{6}$

Other conditions. Non-specific chest pain was associated with a diagnosis of COPD in the year before the index date. It was also found that patients consulting for non-specific chest pain had an approximate threefold increased risk of receiving a diagnosis of respiratory conditions such as asthma or pneumonia in the year following the index date. There is very little published evidence of an association between asthma and non-cardiac chest pain; however, it is possible that the chest tightness associated with asthma may be diagnosed as chest pain. Another possibility is that, as with non-cardiac chest pain, asthma has been associated with GORD, which perhaps further implicates GORD as an underlying factor in non-cardiac or non-specific chest pain. ${ }^{23}$

Musculoskeletal disorders and trauma could also be a cause of non-specific chest pain. A close to twofold increased risk of a new diagnosis of musculoskeletal diseases among patients consulting for non-specific chest pain, was also found which is similar to previously reported values..$^{30,31}$

\section{Implications for future research and clinical practice}

The data here highlight the need for a firm diagnosis to be reached for patients presenting with chest pain in primary care. The data show that at least $80 \%$ of patients who consulted for the first time for nonspecific chest pain did not receive a diagnosis in the 1-year follow-up period that could explain this symptom. Data here have shown that, compared with controls, patients with chest pain that is believed to be non-cardiac in origin are more likely to receive a diagnosis of IHD in the following year. Therefore, it is imperative that caution is exercised when excluding a cardiac cause for chest pain; monitoring is essential for these patients, particularly for those with established risk factors for IHD such as hypertension and hyperlipidaemia.

Chest pain remains a diagnostic challenge in primary care, and patients who do not receive a definitive diagnosis accumulate substantial healthcare costs through frequent primary care and emergency hospital visits, as well as inappropriate drug therapies..$^{32}$ These patients also report a poorer quality of life. ${ }^{1,33,34}$ Prompt diagnosis and treatment are, therefore, essential to optimise the management of these patients.

This study highlights the need for improved methods of differentiating between cardiac and noncardiac chest pain. It also emphasises the need for a firm diagnosis, so future research should concentrate on these areas.

\section{Funding body}

This study was partially supported by an unrestricted research grant from ASTRAZENECA R\&D, Mölndan Sweden

\section{Ethics committee}

Protocol was approved on 21/11/02 by the GPRD Scientific and Ethical Committee (SEAG num ref: 499)

\section{Competing interests}

In addition to the posts listed, Saga Johansson and MariAnn Wallander are also employees of AstraZeneca R\&D Mölndal, Sweden

\section{Acknowledgements}

We thank Dr Catriona Turnbull, of Oxford PharmaGenesis, who provided medical writing support funded by AstraZeneca R\&D Mölndal, Sweden.

\section{Discuss this article}

Contribute and read comments about this article on the Discussion Forum: http://www.rcgp.org.uk/bjgp-discuss

\section{REFERENCES}

1. Eslick GD, Jones MP, Talley NJ. Non-cardiac chest pain: prevalence, risk factors, impact and consulting — a population-based study. Aliment Pharmacol Ther 2003; 17(9): 1115-1124.

2. Locke GR III, Talley NJ, Fett SL, et al. Prevalence and clinical spectrum of gastroesophageal reflux: a population-based study in Olmsted County, Minnesota. Gastroenterology 1997; 112(5): 1448-1456.

3. Lampe FC, Whincup PH, Wannamethee SG, et al. Chest pain on questionnaire and prediction of major ischaemic heart disease events in men. Eur Heart J 1998; 19(1): 63-73.

4. Flook N, Unge P, Agréus L, et al. Approach to managing undiagnosed chest pain: could gastroesophageal reflux disease be the cause? Can Fam Physician 2007; 53(2): 261-266.

5. Wong WM, Lai KC, Lau CP, et al. Upper gastrointestinal evaluation of Chinese patients with non-cardiac chest pain. Aliment Pharmacol Ther 2002; 16(3): 465-471.

6. Wong WM, Lam KF, Cheng C, et al. Population based study of noncardiac chest pain in southern Chinese: prevalence, psychosocial factors and health care utilization. World J Gastroenterol 2004; 10(5): 707-712.

7. Eslick GD. Noncardiac chest pain: epidemiology, natural history, health care seeking, and quality of life. Gastroenterol Clin North Am 2004; 33(1): 1-23.

8. García Rodríguez LA, Pérez Gutthann S. Use of the UK General Practice Research Database for pharmacoepidemiology. Br J Clin Pharmacol 1998; 45(5): 419-425.

9. Jick H, Jick SS, Derby LE. Validation of information recorded on general practitioner based computerised data resource in the United Kingdom. BMJ 1991; 302(6779): 766-768.

10. Jick SS, Kaye JA, Vasilakis-Scaramozza C, et al. Validity of the general practice research database. Pharmacotherapy 2003; 23(5): 686-689.

11. Watson DJ, Rhodes T, Guess HA. All-cause mortality and vascular events among patients with rheumatoid arthritis, osteoarthritis, or no arthritis in the UK General Practice Research Database. J Rheumatol 2003; 30(6): 1196-1202.

12. Lawrenson R, Wyndaele JJ, Vlachonikolis I, et al. A UK general practice database study of prevalence and mortality of people with neural tube defects. Clin Rehabil 2000; 14(6): 627-630.

13. Ruigómez A, Johansson S, Wallander MA, García Rodríguez LA. Predictors and prognosis of paroxysmal atrial fibrillation in general practice in the UK. BMC Cardiovasc Disord 2005; 5: 20.

14. Wilhelmsen L, Rosengren A, Hagman M, Lappas G. 'Nonspecific' chest pain associated with high long-term mortality: results from the primary prevention study in Göteborg, Sweden. Clin Cardiol 1998; 21(7): 477-482.

15. Kachintorn U. How do we define non-cardiac chest pain? $J$ Gastroenterol Hepatol 2005; 20 Suppl: S2-5.

16. Kohn MA, Kwan E, Gupta M, Tabas JA. Prevalence of acute myocardial infarction and other serious diagnoses in patients presenting to an urban emergency department with chest pain. $J$ Emerg Med 2005; 29(4): 383-390. 
17. Sekhri N, Feder GS, Junghans C, et al. How effective are rapid access chest pain clinics? Prognosis of incident angina and non-cardiac chest pain in 8762 consecutive patients. Heart 2007; 93(4): 458-463.

18. Hewson EG, Sinclair JW, Dalton CB, Richter JE. Twenty-four-hour esophageal $\mathrm{pH}$ monitoring: the most useful test for evaluating noncardiac chest pain. Am J Med 1991; 90(5): 576-583.

19. De Caestecker JS, Blackwell JN, Brown J, Heading RC. The oesophagus as a cause of recurrent chest pain: which patients should be investigated and which tests should be used? Lancet 1985; 2(8465) 1143-1146.

20. Fruergaard P, Launbjerg J, Hesse B, et al. The diagnoses of patients admitted with acute chest pain but without myocardial infarction. Eur Heart J 1996; 17(7): 1028-1034.

21. DeMeester TR, O'Sullivan GC, Bermudez G, et al. Esophageal function in patients with angina-type chest pain and normal coronary angiograms. Ann Surg 1982; 196(4): 488-498.

22. Nilsson S, Scheike M, Engblom D, et al. Chest pain and ischaemic heart disease in primary care. Br J Gen Pract 2003; 53(490): 378-382.

23. Vakil N, van Zanten SV, Kahrilas P, et al. The Montreal definition and classification of gastroesophageal reflux disease: a global evidencebased consensus. Am J Gastroenterol 2006; 101(8): 1900-1920.

24. Heading RC. Review article: diagnosis and clinical investigation of gastro-oesophageal reflux disease: a European view. Aliment Pharmacol Ther 2004; 20 Suppl 8: 9-13.

25. Heatley M, Rose K, Weston C. The heart and the oesophagus: intimate relations. Postgrad Med J 2005; 81(958): 515-518.

26. Cremonini F, Wise J, Moayyedi P, Talley NJ. Diagnostic and therapeutic use of proton pump inhibitors in non-cardiac chest pain: a metaanalysis. Am J Gastroenterol 2005; 100(6): 1226-1232.

27. Cayley WE Jr. Diagnosing the cause of chest pain. Am Fam Physician 2005; 72(10): 2012-2021.

28. Hamer HP, McCallin AM. Cardiac pain or panic disorder? Managing uncertainty in the emergency department. Nurs Health Sci 2006; 8(4): 224-230.

29. Fleet RP, Dupuis G, Marchand A, et al. Panic disorder in emergency department chest pain patients: prevalence, comorbidity, suicidal ideation, and physician recognition. Am J Med 1996; 101(4): 371-380.

30. Mukerii B, Mukerii V, Alpert MA, Selukar R. The prevalence of rheumatologic disorders in patients with chest pain and angiographically normal coronary arteries. Angiology 1995; 46(5): 425-430.

31. Jensen S. Musculoskeletal causes of chest pain. Aust Fam Physician 2001; 30(9): 834-839.

32. Fang J, Bjorkman D. A critical approach to noncardiac chest pain: pathophysiology, diagnosis, and treatment. Am J Gastroenterol 2001; 96(4): 958-968.

33. Atienza F, Velasco JA, Brown S, et al. Assessment of quality of life in patients with chest pain and normal coronary arteriogram (syndrome X) using a specific questionnaire. Clin Cardiol 1999; 22(4): 283-290.

34. Karlson BW, Wiklund I, Bengtson A, Herlitz J. Prognosis, severity of symptoms, and aspects of well-being among patients in whom myocardial infarction was ruled out. Clin Cardiol 1994; 17(8): $427-431$. 


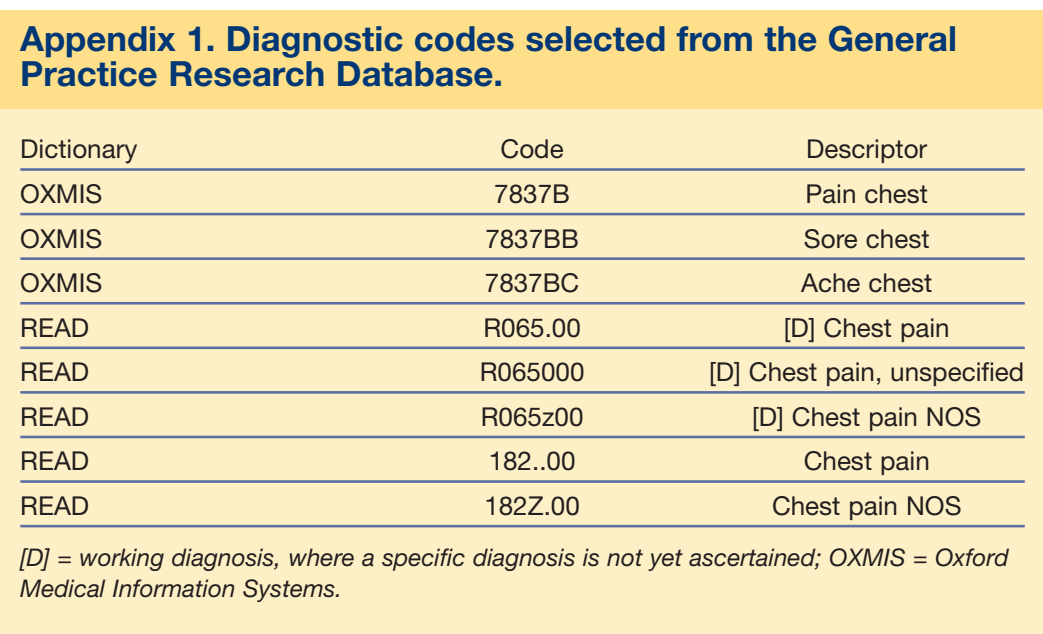

\begin{tabular}{|c|c|c|}
\hline & Crude HR (95\% Cl) & Adjusted $^{\mathrm{a}} \mathrm{HR}(95 \% \mathrm{Cl})$ \\
\hline 1-year mortality & 2.4 (1.4 to 4.1$)$ & 2.3 (1.3 to 4.1$)$ \\
\hline 1-year IHD diagnosis & 18.2 (11.7 to 28.3$)$ & 18.2 (11.6 to 28.6$)$ \\
\hline 1-year MI & $4.6(1.9$ to 11.2$)$ & 4.1 (1.6 to 10.3$)$ \\
\hline
\end{tabular}

